\title{
Molecular geometry optimization of 5-(Hydroxy methyl) furan-2-carbaldehyde and 3,5-dihydroxy- 6-methyl-2,3-dihydro-4H-pyran-4-One active phytocompounds from ethanol leaf extract of huru crepitans and its in vivo antimicrobial activities
}

\begin{abstract}
Geometry optimization of 5-(hydroxymeth yl)furan-2-carbaldehyde and 3,5-dihydroxy6-methyl-2,3-dihydro-4H-pyran-4-one (active phytocompounds) from the ethanol leaf extract of Huru crepitans were studied using ArgusLab 4.0.1 software. Minimization was performed with semi-empirical Austin Model 1 (AM1) parameterization. The minimum potential energy was calculated by using geometry convergence function in ArgusLab software. Surfaces were created to visualize the highest occupied molecular orbital (HOMO), lowest unoccupied molecular orbital (LUMO) and electrostatic potential mapped on electron density surface. The minimum potential energy was calculated for drug receptor interaction through the geometry convergence map. The minimum energy for 5-(hydroxymethyl) furan-2-carbaldehyde and 3, 5-dihydroxy-6-methyl-2,3-dihydro$4 H$-pyran-4-one were -40.47 au $(-25397.71 \mathrm{kcal} / \mathrm{mol})$ and -74.97 au $(-47045.04 \mathrm{kcal} /$ mol) respectively. At this point these two active compounds of $H$. crepitans will be more active as an antimicrobial agent. It is possible that $H$. crepitans will interact with receptor in these conformations. The antimicrobial effects of the phytochemicals in the extracts of Huru crepitans were assessed and evaluation was done against infectious micro organisms; Staphylococcus aureus, Proteus vulgaris, Escherichia coli, Klebsiella pneumonia and Candida albican. The antibacterial activity of the plants was evaluated using Agar gel diffusion method and the minimal inhibitory concentration (MIC) was determined by broth assay method. The extract was tested at varied concentrations of $250 \mathrm{mg} / \mathrm{ml}, 200 \mathrm{mg} / \mathrm{ml}, 100 \mathrm{mg} / \mathrm{ml}, 50 \mathrm{mg} / \mathrm{ml}$ and $10 \mathrm{mg} / \mathrm{ml}$ on these five organisms. The Mean Inhibition Zone Diameter (IZD) of Staphylococcus aureus was 4.6 $\pm 1.10,8.8 \pm 0.32$, $12.6 \pm 0.89,13.4 \pm 1.14,18.6 \pm 1.14$ compared to the reference drug $10.10 \pm 0.26$ at $\mathrm{p}<0.05$. That of Proteus vulgaris was $5.3 \pm 0.30,7.2 \pm 0.49,8.4 \pm 0.21,8.4 \pm 0.38,12.4 \pm 0.49,16.6 \pm 0.55$ compared to the reference drug $7.6 \pm 0.54$ at $\mathrm{p}<0.05$. Escherichia coli mean Inhibition Zone Diameter (IZD) was $4.6 \pm 0.31,6.1 \pm 0.73,16.0 \pm 0.89,18.5 \pm 0.66,20.7 \pm 0.76$ compared to the reference drug $16.8 \pm 0.48$ at $(\mathrm{p}<0.05)$. Klebsiella pneumonia was $6.1 \pm 0.44,10.0 \pm 0.31$, $14.2 \pm 0.33,16.0 \pm 0.16,21.6 \pm 1.73$ compared to the reference drug $13.3 \pm 0.12(\mathrm{p}<0.05)$ The Mean Inhibition Zone Diameter (IZD) of Candida albicans was $3.8 \pm 0.23,5.2 \pm 0.24$, $6.5 \pm 0.28,7.4 \pm 0.14,8.0 \pm 0.69$ compared to the reference drug $00.0 \pm 0.00(\mathrm{p}<0.05)$. The reference drug had no effect on Candida albicans. This shows that phytochemicals in $H$. crepitans bark extract are effective against bacteria and fungi therefore could be adopted for pharmacological use.
\end{abstract}

Keywords: geometry optimization, antimicrobe, huru crepitans, medicinal plant
Volume 5 Issue I - 2017

\author{
Ikpeazu OV,' Igwe KK, ${ }^{2}$ Otuokere $\mathrm{IE}^{3}$ \\ 'Department of Biochemistry,Abia State University, Nigeria \\ ${ }^{2}$ Department of Vet Biochemistry and Pharmacology, Michael \\ Okpara University of Agriculture, Nigeria \\ ${ }^{3}$ Department of Chemistry, Michael Okpara University of \\ Agriculture, Nigeria
}

Correspondence: Igwe KK, Department of Vet Biochemistry and Pharmacology, Michael Okpara University of Agriculture, Umudike, Tel +234(0)706529763l;

Email ifeanyiotuokere@gmail.coom

Received: June 0I, 2017 | Published: June 13, 2017
Abbreviations: AM1, austin model 1 parameterization; HOMO, highest occupied molecular orbital; LUMO, lowest unoccupied molecular orbital; MIC, minimal inhibitory concentration; IZD, inhibition zone diameter

\section{Introduction}

Applications of phytochemicals in pharmacology are of increasing clinical and commercial importance. Literature publications testify to the growing importance of the discipline and reviews have been published in pharmacognosy. Lists of some clinically used phytochemical agents may be found in most Duck's work. ${ }^{1}$ Several researches have worked on the identification and bioactivities of phytochemicals in $H$. crepitans by GCMS analysis. ${ }^{2}$ Plants have been used as medicine for curing various ailments and preventing diseases in man and animals. They also play an essential role in religion and development of human culture. ${ }^{3}$. Analysis of the phytochemicals in medicinal plants helps us to understand the compounds in them that provide us with those medicinal activities for effective health delivery. $H$. crepitans from the family of Euphorbiaceae (spurge) is an evergreen tree that is native to the tropical regions of the Amazon forest and also the North and South America. Its synonyms are $H$. strepens Willd, H. brasiliensis Willd and H. senegalensis Baill. ${ }^{4}$ This plant is also known as sandbox tree, possum wood, jabillo and dynamite tree because of the explosive sound it makes as it splits the capsule. ${ }^{5} H$. crepitans can grow up to $200 \mathrm{ft}(60 \mathrm{~m})^{6}$ and the fruit it produces is in form of a large capsule that can explode, spreading its 
seeds as far as 160 meters per hour ${ }^{7}$ or as far as $330 \mathrm{ft}^{8}$ from the tree. The plant is known by possessing many dark pointed sharp spines on its smooth bark. These spines prevent animals from climbing it. ${ }^{9,10}$ The plant is usually cultivated for shade and the wood used for making furniture, while the milky sap serves as poison for arrows ${ }^{11}$ and for catching fishes by fishermen. ${ }^{12}$. H. crepitans is cultivated for medicinal purposes as it is used in treating skin diseases, intestinal worm and srheumatism. Its bark is used to treat leprosy and the leaves used to treat eczema. ${ }^{11}$. Phytochemicals in plant extracts have been identified using GCMS analysis by different researchers. ${ }^{12-16}$ thus we use the same analysis to identify the phytochemicals in ethanol extract of $H$. Crepitans that demonstrated antimicrobial activity as preliminary study and carried out in vivo study on selected microbes.

The purpose of geometry optimization is to determine atomic orientations that are stable. The most stable conformation is one with the least energy. ArgusLab ${ }^{17}$ is a molecular modeling graphics and drug design program for windows operating system. This research is aimed at confirming the final geometry energy and antimicrobial activities of 5-(hydroxymethyl)furan-2-carbaldehyde and 3, 5-dihydroxy-6methyl-2,3-dihydro- $4 H$-pyran-4-one (active phytocompounds) from the ethanol leaf extract of $H$. crepitans. The pictorial view of $H$. crepitansbark and leaf are shown in Figure 1A \& 1B respectively. The structures of 5-(hydroxymethyl) furan-2-carbaldehyde and 3, 5-dihydroxy-6-methyl-2,3-dihydro- $4 H$-pyran-4-one as proposed in our previous publication ${ }^{2}$ are shown in Figure $2 \mathrm{~A} \& 2 \mathrm{~B}$ respectively.

\section{Materials and method}

\section{Geometry optimization}

Geometry optimization study was performed on a window based computer using ArgusLab and ACD Lab ChemSketch softwares. The chemical structures of 5-(hydroxymethyl) furan-2-carbaldehyde and 3, 5-dihydroxy-6-methyl-2,3-dihydro-4H-pyran-4-one were generated by ArgusLab, minimization was performed with semi-empirical Austin Model 1 (AM1) parameterization. The minimum potential energy was calculated by using geometry convergence function in ArgusLab software. Surfaces created to visualize the highest occupied molecular orbital (HOMO), lowest unoccupied molecular orbital (LUMO) and electrostatic potential mapped on electron density surface. The minimum potential energy was calculated for drug receptor interaction through the geometry convergence map.

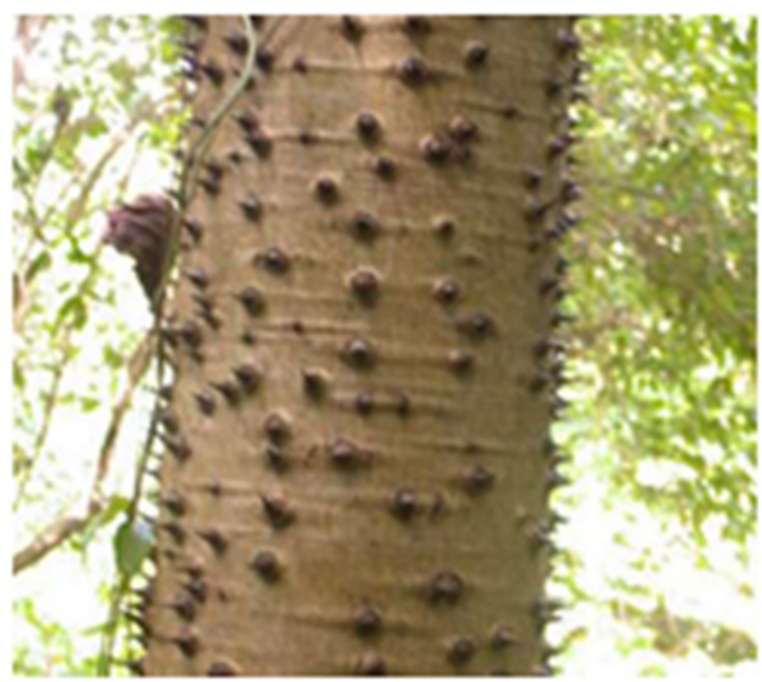

Figure I A Pictorial view of $H$. crepitans bark.

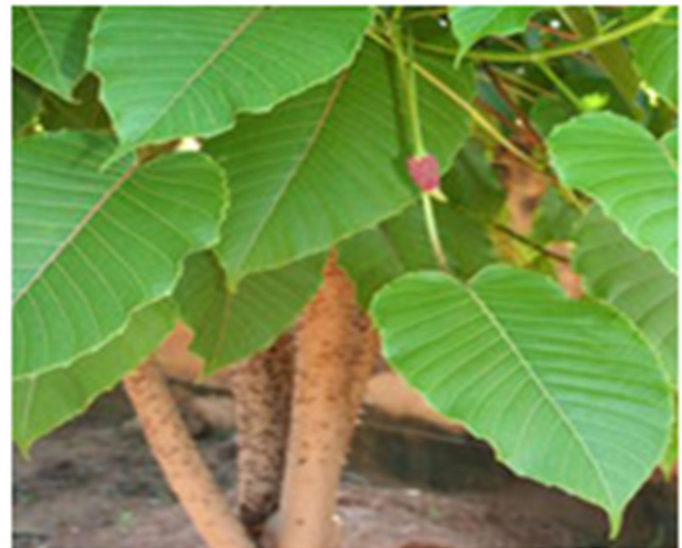

Figure IB Pictorial view of $H$. crepitans bark and leaves.

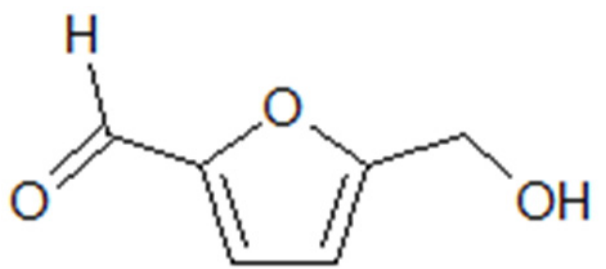

Figure 2A 5-(hydroxymethyl) furan-2-carbaldehyde.

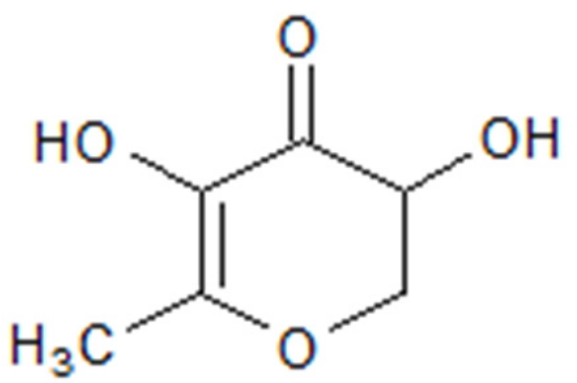

Figure 2B 3,5-dihydroxy-6-methyl-2,3-dihydro-4H-pyran-4-one.

\section{Plant materials}

Fresh bark of Huru crepitanswas harvested at Umudike town in Abia State, Nigeria. The plant was identified in the Taxonomy section of College of Natural Resources and Environmental Management, Michael Okpara University of Agriculture, Umudike, Nigeria.

\section{Preparation of plant extract}

The plant materials of $H$. crepitans were collected from the wild, shade dried for 10 days and pulverized to powder using mechanical grinder. The plant extract was prepared using Soxhlet method described by. ${ }^{18}$ Thirty five grams $(35 \mathrm{~g})$ of powdered sample was introduced into the extraction chamber of the Soxhlet extractor using ethanol as solvent. Temperature was maintained at $75^{\circ} \mathrm{C}$ throughout the extraction period of $48 \mathrm{hrs}$. At the end of the period, the extract was concentrated using oven at $35^{\circ} \mathrm{C}$ to obtain dried sample ready for in vivo antimicrobial studies.

\section{Isolation of staphylococcus aureus}

Nasal swabs were collected from goat and sample was cultured in mannitol salt media. Golden yellow colonies were observed on the media which is diagnostic for Staphylococcus aureus. Gram staining

Citation: Ikpeazu OV, Igwe KK, Otuokere IE. Molecular geometry optimization of 5-(Hydroxy methyl) furan-2-carbaldehyde and 3,5-dihydroxy-6-methyl2,3-dihydro-4H-pyran-4-One active phytocompounds from ethanol leaf extract of huru crepitans and its in vivo antimicrobial activities.J Anal Pharm Res. 20I7;5(I): I-6. DOI: I0.15406/japlr.20I7.05.00I3I 
and catalase and coagulase test was carried out to confirm organism as staphylococcus.

\section{Isolation of $E$ coli, proteus vulgaris, klebsiella pneumonia and candida albicans}

The samples were re-isolated from pure stock in the Veterinary Microbiology laboratory in a MacConkey media. Gram staining was done to confirm Gram negative and positive organisms.

\section{Preparation of single-antibiotic discs}

100 discs were obtained from punching a No. 1 whatman paper disc and sterilized in a hot air oven at $160^{\circ} \mathrm{C}$ and $1 \mathrm{mlx} 100$ of the re-constituted chloramphenicol solution was pipette into bijou bottle containing the sterile disc and dried in a hot air oven at $60^{\circ} \mathrm{C}$.

\section{Antibiotic sensitivity test}

An agar well diffusion method was used for the antibiotic sensitivity test. This was done by preparing a nutrient media and the organisms inoculated into the media and incubated for 2 hours Template aseptically was made using a cork borer on one end and the different concentration of extract placed in it. The chloramphenicol disc was placed on the other end of the dish. The plate was incubated overnight and read by measuring the diameter of zone of inhibition for each concentration of $H$. crepitans bark.

\section{Media preparation}

The media used for the antimicrobial sensitivity testing was Muller Hinton agar. It was prepared by weighing out $38 \mathrm{~g}$ of the powered agar into $100 \mathrm{ml}$ of distilled water in a conical flask. This was sterilized in an autoclave at $121^{\circ} \mathrm{C}$ for 15 minutes, after autoclave, the media was poured into sterile petri dish and allowed to cool and gel.

\section{Determination of antimicrobial activity}

The organisms used are Escherichia coli ((2 strains) from the family of Enterobactriaceae and Staphylococcus aureus (2 strains) from the family of Staphylococcus. Stock culture in Vet. Microbiology lab was inoculated into the already prepared Muller Hinton agar. Using a cork borer, well $(7 \mathrm{~mm}$ in diameter and $2.5 \mathrm{~mm}$ deep) was bored into the inoculated agar and $50 \mu \mathrm{l}$ of each of the extract at a concentration of $1 \mathrm{~g} / \mathrm{ml}$ was delivered into the wells. The plates were incubated $35^{\circ} \mathrm{C}$ and read after 24 hours. The diameter zones of inhibition produced by the extract were measured with a transparent meter rule in $\mathrm{mm}$.

\section{Determination of minimum inhibitory concentration (MIC)}

The minimum inhibitory concentration (MIC) is the lowest concentration of antimicrobial extract that inhibited the visible growth of the microorganism after overnight incubation. This was determined by Mueller Hinton agar method. ${ }^{19}$ To determine the MIC $1.0 \mathrm{~mL}$ of Mueller Hinton Broth was transferred into 9 test tubes. One $(1 \mathrm{ml})$ of the extract at $50 \mathrm{mg} / \mathrm{ml}$ was pipette into the first tube and mixed properly. One $(1 \mathrm{ml})$ was taken from the first test tube into the second test tube and mixed. This was continued up to the 7 th tube to give concentrations of $25,12.5,6.25,3.12,1.56,0.78$ and $0.39 \mathrm{mg} / \mathrm{ml}$. The 8thtube was labelled the organism control which contained only the organisms and Mueller Hinton Broth but no extract. The 9th tube was labelled antibiotic control which contained the organism, Mueller Hinton Broth and antibiotic. Volume $0.05 \mathrm{ml}$ (50ul) of the organism suspension was transferred into each test tube using a micropipette. The tubes were incubated at $35^{\circ} \mathrm{C}$ and result read after 24 hours. The MIC was the concentration that prevented visible growth of the organism after the period of incubation of 24 hours.

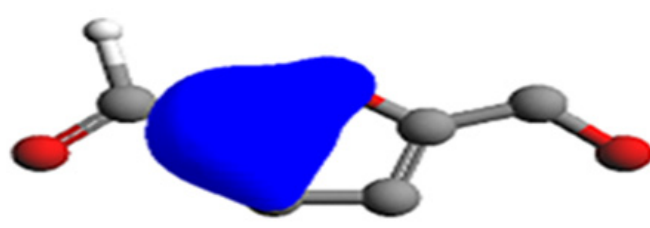

Figure 3 Highest occupied molecular orbital (HOMO) of 5-(hydroxymethyl) furan-2-carbaldehyde.

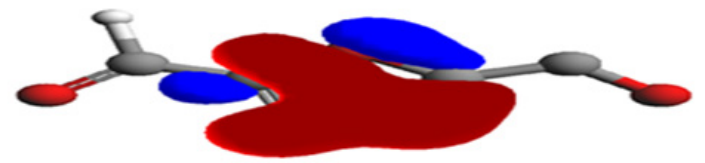

Figure 4 Lowest unoccupied molecular orbital (LUMO) of 5-(hydroxymethyl) furan-2-carbaldehyde.

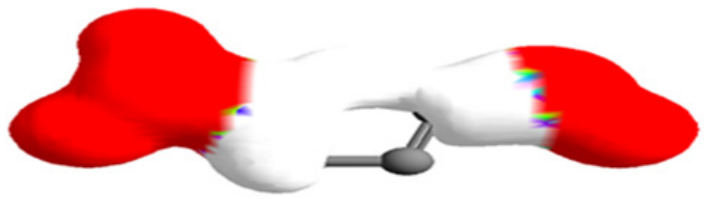

Figure 5 Electrostatic potential mapped on electron density surface for 5-(hydroxymethyl)furan-2-carbaldehyde.

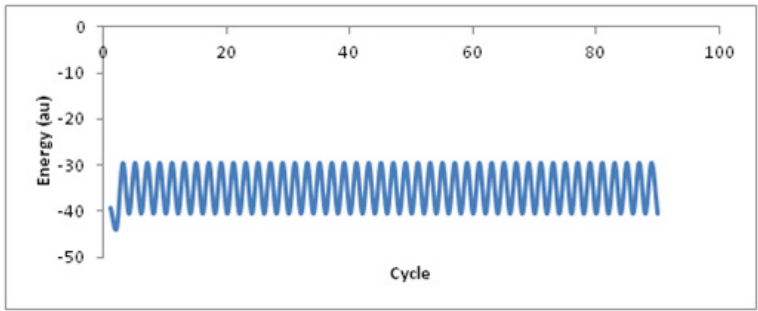

Figure 6 Geometry convergence map for 5-(hydroxymethyl) furan-2carbaldehyde.

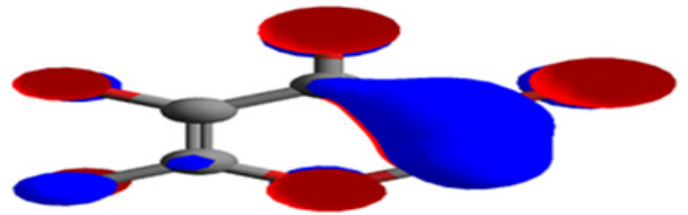

Figure 7 Highest occupied molecular orbital (HOMO) of 3, 5-dihydroxy-6methyl-2,3-dihydro-4H-pyran-4-one.

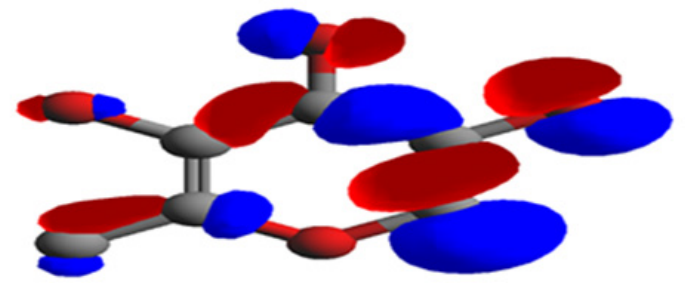

Figure 8 Lowest unoccupied molecular orbital (LUMO) of 3, 5-dihydroxy-6methyl-2,3-dihydro-4H-pyran-4-one.

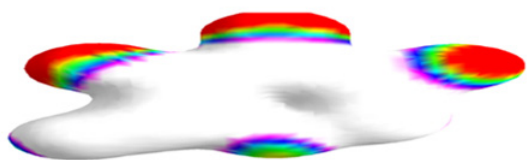

Figure 9 Electrostatic potential mapped onto the electron density surface of 3, 5-dihydroxy-6-methyl-2,3-dihydro-4H-pyran-4-one. 


\begin{tabular}{|c|c|c|c|c|c|c|}
\hline 0 & & & & & & \\
\hline-100 & 20 & 40 & 60 & 80 & 100 & 120 \\
\hline-20 & & & & & & \\
\hline 亨-30 & & & & & & \\
\hline खे -40 & & & & & & \\
\hline 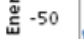 & & & & & & \\
\hline-60 & & & & & & \\
\hline $\begin{array}{l}-70 \\
-80\end{array}$ & & & & & & \\
\hline
\end{tabular}

Figure 10 Geometry convergence map of 3, 5-dihydroxy-6-methyl-2,3dihydro-4H-pyran-4-one.

\section{Data analysis}

Data collected were analyzed using SPSS version 17 software. All values were expressed as the mean value \pm standard deviation by one way ANOVA for comparisons of the multiple means. It was followed by post hoc test to compare their differences. $(\mathrm{p}<0.05)$ was considered statistically significant difference between test and control groups for measured values.

\section{Results and discussion}

The highest occupied molecular orbital (HOMO), lowest unoccupied molecular orbital (LUMO), electrostatic potential mapped on electron density surface, geometry convergence map of 5-(hydroxymethyl) furan-2-carbaldehyde are shown in Figure 3-6 respectively. The highest occupied molecular orbital (HOMO), lowest unoccupied molecular orbital (LUMO), electrostatic potential mapped on electron density surface, geometry convergence map of for 3, 5-dihydroxy-6-methyl-2,3-dihydro-4H-pyran-4-one are presented in Figures 7-10 respectively. The minimum inhibition concentration (MIC) $\mathrm{mg} / \mathrm{ml}$ of the extract and mean inhibition zone diameter (IZD) $\mathrm{mm}$ of different organisms are presented in Figures 11-15.

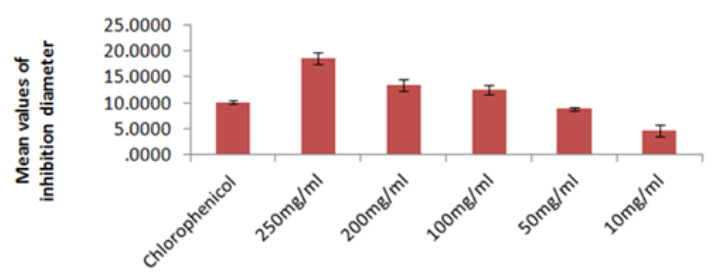

Figure II Graph showing mean inhibition zone diameter of Staphylococcus aureus.

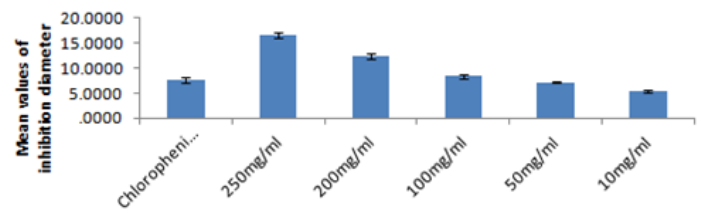

Figure 12 Graph showing mean inhibition zone diameter of Proteus vulgaris.

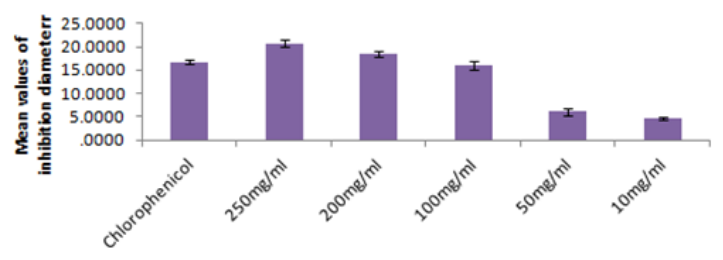

Figure I3 Graph showing mean inhibition zone diameter of Escherichia coli.

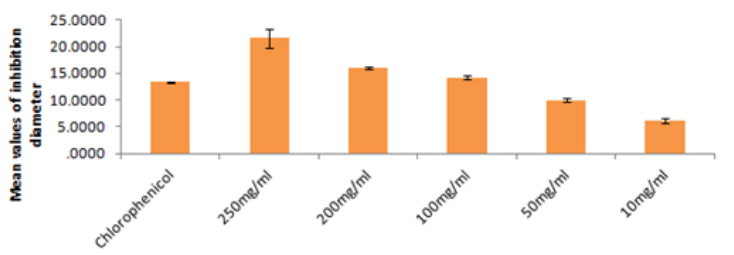

Figure I4 Graph showing mean inhibition zone diameter of Klebsiella pneumonia.

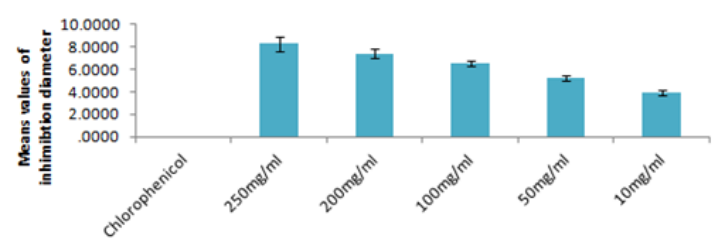

Figure I5 Graph showing mean inhibition zone diameter of Candida albicans.

ArgusLab was used to create mapped surfaces. The electrostatic potential surface was mapped onto the electron density. The electrostatic potential represents the colour while the electron density represents the shape of the molecule. Negative electrostatic potential shows stability for a positive test charge while positive electrostatic potential shows instability for a positive test charge. Thus an electrostatic potential mapped density surface might give information about nucleophilic or electrophilic attack. This enables the Chemist to determine the chemical reactivity of the drug. The red color indicates the most negative regions of the electrostatic potential where a positive test charge would have favorable interaction energy. For 5-(hydroxymethyl) furan-2-carbaldehyde, the negative regions are the $\mathrm{COOH}$ and $\mathrm{OH}$ functional groups. The ring portion of the molecule with the white color, shows regions of relatively unfavorable energy for the electrostatic potential. For 3, 5-dihydroxy-6-methyl2,3-dihydro-4H-pyran-4-one, the negative regions are the $\mathrm{OH}$ and $\mathrm{C}=\mathrm{O}$ functional groups. The methyl-end of the molecule, with the magenta color, shows regions of relatively unfavorable energy for the electrostatic potential.

Highest occupied molecular orbital (HOMO) is the highest energy molecular orbtal that has electron in it. The Lowest unoccupied molecular orbital (LUMO) is the next lowest energy orbital in which an excited electron will occupy. The red regions represent high electron density (negative) while the blue regions indicate low electron density (positive).

The minimum energy for 5-(hydroxymethyl)furan-2-carbaldehyde and 3, 5-dihydroxy-6-methyl-2,3-dihydro-4H-pyran-4-one were $-40.47 \mathrm{au}(-25397.71 \mathrm{kcal} / \mathrm{mol})$ and $-74.97 \mathrm{au}(-47045.04 \mathrm{kcal} /$ mol) respectively. At this point these two active compounds of $H$. crepitans will be more active as an antimicrobial agent. It is possible that $H$. crepitans will interact with receptor in these conformations.

In Figure 11 there was concentration dependent increase in inhibition of the organisms by the extract $4.6 \pm 1.10,8.8 \pm 0.32$, $12.6 \pm 0.89,13.4 \pm 1.14,18.6 \pm 1.14$ as the concentration increased from $10 \mathrm{mg} / \mathrm{ml}$ to $250 \mathrm{mg} / \mathrm{ml}$ when compared to the reference drug $10.10 \pm$ $0.26(p<0.05)$. The extract inhibited the growth of Staphylococcus aureus significantly.

Figure 5 showed a concentration dependent increase in inhibition of Proteus vulgarisby the extract $5.3 \pm 0.30,7.2 \pm 0.49$, $8.4 \pm 0.21,8.4 \pm 0.38, \quad 12.4 \pm 0.49, \quad 16.6 \pm 0.55$ as the concentration increased from $10 \mathrm{mg} / \mathrm{ml}$ to $250 \mathrm{mg} / \mathrm{ml}$, when compared to the 
reference drug $7.6 \pm 0.54(\mathrm{p}<0.05)$. The extract inhibited the growth of the Proteus vulgaris significantly.

From Figure 6 it was deduced that there was concentration dependent increase in inhibition of Escherichia coliby the extract $4.6 \pm 0.31, \quad 6.1 \pm 0.73, \quad 16.0 \pm 0.89, \quad 18.5 \pm 0.66, \quad 20.7 \pm 0.76$ as the concentration of Huru crepitan increased from $10 \mathrm{mg} / \mathrm{ml}$ to $250 \mathrm{mg} / \mathrm{ml}$ and compared to the reference drug $16.8 \pm 0.48(\mathrm{p}<0.05)$. The extract inhibited the growth of Escherichia colisignificantly.

From the graph Figure 7, it is shown that there was concentration dependent increase in inhibition of Klebsiella pneumoniaby the extract $6.1 \pm 0.44,10.0 \pm 0.31,14.2 \pm 0.33,16.0 \pm 0.16,21.6 \pm 1.73$ as the concentration of Huru crepitan increased from $10 \mathrm{mg} / \mathrm{ml}$ to $250 \mathrm{mg} / \mathrm{ml}$ and compared to the reference drug $13.3 \pm 0.12(\mathrm{p}<0.05)$. The extract also inhibited the growth of Klebsiella pneumoniasignificantly.

The graph, Figure 8 shows concentration dependent increase in inhibition of Candida albicans by the extract $3.8 \pm 0.23,5.2 \pm 0.24$, $6.5 \pm 0.28,7.4 \pm 0.14,8.0 \pm 0.69$. The reference drug had no effect on Candida albicans. There was high inhibition of the growth of Candida albicans by the Hura crepitans bark extract as the concentration of Huru crepitans increased from $10 \mathrm{mg} / \mathrm{ml}$ to $250 \mathrm{mg} /$ $\mathrm{ml}$ and compared to the reference drug $00.0 \pm 0.00(\mathrm{p}<0.05)$.

\section{Conclusion}

The phytochemicals, 5-(hydroxymethyl) furan-2-carbaldehyde and 3, 5-dihydroxy-6-methyl-2,3-dihydro-4H-pyran-4-one in $H$. crepitans were geometrically optimized. The minimum energy of the phytochemicals were $-40.47 \mathrm{au}(-25397.71 \mathrm{kcal} / \mathrm{mol})$ and -74.97 au $(-47045.04 \mathrm{kcal} / \mathrm{mol})$ respectively. At this point these two active compounds in $H$. crepitans will be more active as antimicrobial agent. It is possible that $H$. crepitans will interact with receptor in these conformations. The in vivo antimicrobial studies confirmed that H. crepitans inhibited Staphylococcus aureus, Proteus vulgaris, Escherichia coli, Klebsiella pneumonia and Candida albican

\section{Acknowledgements}

We are grateful for the research grant from Abia State Government, Nigeria.

\section{Conflicts of interest}

The authors declare no conflicts of interest related to this article.

\section{Funding}

None.

\section{References}

1. https://phytochem.nal.usda.gov/phytochem/search
2. Igwe KK, Nwankudu ON, Ijioma SN, et al. Screening for secondary metabolites in Huru crepitansbark ethanol extract using GC-MS analysis:a preliminary study approach. JSTA. 2016;(2):64-71.

3. Swain T. Plants in the Development of Modern Medicine. USA: Harvard University Press; 1968.

4. The Plant List: A Working List of All Plant Species. UK: Record kew, $100851 ; 1968$.

5. Radcliffe-Smith A. A review of the family Euphorbiaceae. Nat Occ Phorbol Est. 1986.

6. Swain MD, Beer T. Explosive Seed Dispersal in H. crepitans L. (Euphorbiaceae). New Phytologist. 1977;78:695-708.

7. Vogel S. The Flight of the Seed of H. crepitans. USA: Duke University; 2008

8. Feldkamp. Susan Modern Biology. USA: Holt, Rinehart, and Winston; 2006. pp. 618.

9. Jones DE.Poison Arrows:North American Indian Hunting and Warfare. USA: University of Texas Press; 2007.

10. http://volnomuvolya.com/useful_plants_in_the_tropical_forest.html

11. http://www.tropilab.com/

12. Igwe KK, Madubuike AJ, Chika I, et al. Studies of the medicinal plant Pausinystalia yohimbe ethanol leaf extract phytocomponents by GCMS Analysis. International Journal of Science Research and Management. 2016;4(5):4116-4122.

13. Xu, CJ, Liang YZ, Chau FT, et al. Pretreatments of chromatographic fingerprints for quality control of herbal medicines. $J$ Chromatogr $A$. 2006;1134(1-2):253-259.

14. Madubuike AJ, Igwe KK, Otuokere IE, et al. Bioactivity evaluation study of Phytochemicals in GouaniaLongipetala ethanol leaf extract using GC-MS analysis. International Journal of Scientific and Technical Research in Engineering. 2006;1(5):63-71.

15. Zhu H, Wang Y, Liang H, et al. Identification of Portulaca oleracea L. from different sources using GC-MS and FT-IR spectroscopy. Talanta. 2010;81(1-2):129-135.

16. Otuokere IE, Okorie DO, Orieke BE, et al. Characterization of Costus afer Stem Ethanol Extract by Gas Chromatography-Mass Spectrometry Analysis. International Journal of Basic and Applied Chemical Sciences. 2016;6(2):79-84.

17. http://www.arguslab.com

18. Jensen WB. The origin of Soxhlex Extraction. Journal Clinical Education. 2007;84(12):1913-1914.

19. Oxoid Manual. The oxoid manual of culture media ingredients and other laboratory services. 5th edn. London, England; 1982. pp. 212-214. 